\title{
Encouraging Psychiatric Trainees to Undertake Research
}

\author{
A Preliminary Account of a New Course
}

By David Goldberg, Professor of Psychiatry, University of Manchester

\begin{abstract}
'Prominent among the obligations of those who provide postgraduate education', wrote Aubrey Lewis in 1961, 'is the duty to recognize and further whatever talents for research their students possess'. He was largely responsible for introducing a system whereby those who wished to train at the Maudsley were expected to carry a modest research project as part of their DPM examination, although he was aware that 'it is profitless, and can be unkind, to encourage competent clincians to attempt scientific investigations beyond their powers'. In the 14 years since his retirement. research by trainees has gone into a decline, so that even at the Maudsley only a minority are actively engaged in research. Crammer (1979) writes 'People thought (research) would help them to a consultant posi. Now they know it is not necessary. Training has become more formalized, with day-release courses and rotation schemes ...' Creed and Murray (1981) have made a detailed study of the views of Maudsley trainees about the way they were taught clinical skills; they have shown that between 1974 and 1977 there was a decline in the number of units which encouraged the trainee to undertake research, and that over the whole period only 27 per cent of the units gave trainees such encouragement. These investigators found that encouragement to do research was transmitted quite independently of other clinical teaching, so that it bore no relationship to variables such as the excellence of the academic instruction, feedback from the consultant, or workload.
\end{abstract}

In Manchester, most trainees on the rotational scheme based on the teaching hospitals are registered on the course leading to the MSc (Psychiatry) of the University of Manchester, which is a degree partly based on course work and partly on a dissertation. This course is half day a week over two academic years, and is supplementary to our combined MSc/MRCPsych course, which is one day a week spread over three years. The MSc course contains systematic instruction in research methodology and statistical method in addition to seminars and other teaching unrelated to research. In addition, a 'Research Society' meets every other week, and allows trainees to hear presentations by psychiatrists, clinical psychologists and other social scientists.

The trainees are expected to discuss possible research projects in their second year, and need not submit their dissertation until well after they have taken the Membership examination. However, many trainees delay producing their ideas for their research, and are self-conscious about the tentative ideas they have had. Listening to critical discussions of papers at journal clubs, hearing presentations of major projects at the research society and listening to the complexities of multivariate statistical techniques on the research methodology course may all have the unintended effect of increasing this self-consciousness.

A new course was therefore designed for those who had not yet registered a project, intended to acquaint trainees with a wide range of one-person projects, and to give them constructive encouragement.

\section{The course}

There were 10 weekly sessions lasting approximately two hours. The introductory session took the form of a lecture about one-man projects, with advice about writing a research proposal, keeping systematic notes, getting the best from one's supervisor, and keeping a project log. A timetable was given out containing advice about how to plan time, and how to make a start on writing up as the field work and data analyses proceed. It was explained that each of the following nine sessions would be given by a different teacher who would cover a particular research area, and the format of a typical afternoon was explained. A volunteer trainee was then found for each teacher and was asked to contact the teacher as soon as possible.

The teachers were all asked to divide the afternoon into two parts. In the first part, they started by describing the problems which were peculiar to their particular area and illustrated their remarks with examples drawn from their personal research. They were asked to avoid intimidating the students with the complexities of research and to illustrate pitfalls with examples that were known to them. Finally, they drew attention to projects which still needed to be done in their area, and which could be done by a single person.

In the second half of the afternoon, the trainee who had volunteered said how he or she would set about doing a project which the teacher had discussed with them. Typical problems concerned which measuring instruments to use, how many subjects to include and how to overcome practical difficulties posed by a particular project. Some trainees chose to have several discussions with the teacher prior to their presentation to the group. All students were told that while they were by no means committed to the project they had prepared, they could have first refusal of it if they wished.

The nine topic areas were decided by the research interests of the available teachers, and consisted of research with the physically ill, life events research, alcoholism, psychopharmacology, drug studies, psychotherapy process research, family studies, research with children and research in general practice. 


\section{Evaluation}

Invitations were sent to fourteen students who had failed to register a title for their research project. Two were unable to attend on that afternoon, and of the twelve who accepted the invitation three claimed to have projects but decided to attend the course anyway; four others said that they had tentative ideas for research, while five had no ideas. At the end of the course, nine ( 75 per cent) had firm plans for research, while the remaining three had made tentative plans.

Students gave their opinion of the course on a form which they did not have to sign; nevertheless, comments were uniformly favourable about the course on the whole, and generally favourable about each individual teacher. One student wrote:

'From the point of view of actually tackling research, this course has been more useful than any in the past two years. Talking about completed, published, large-scale research makes the prospect more daunting and distant. It helped me gauge the size of project that is expected and see that other people have the same difficulties. Practice in protocol writing was useful. The course also helped to identify potential supervisors by their special interests.'

These views were echoed by another student:

'We had the opportunity to discuss each other's projects constructively. It helped to set limits and structure some of the projects more appropriately. Personally, I got a better understanding of what an MSc project should entail and ways of setting about it.'

A third student admired the informal atmosphere, the strong emphasis on feasibility, and the fact that lecturers were realistic without being 'off-putting'. This student added that the presentations had a personal flavour which added to the interest, and said he 'felt closer to his colleagues at the end of the course'.

\section{Comment}

In the past decade we have routinely evaluated our courses and we are therefore familiar with the usual range of responses to our teaching. The warmth of this feedback suggests that we have reduced our trainees' 'anxieties about carrying out their own project.

It is, of course, too early to say whether the new projects will actually be carried out, but there seems little doubt that the course has succeeded in its objective of giving a gentle push to those hesitating on the edge of the swimming pool. No unfavourable comments have been made about the format for each afternoon, so it is our intention to use the same format in subsequent years. The choice of topic areas must, of course, be determined by the teachers who are available and the nature of the research with which they are personally familiar.

It was perhaps inevitable that teachers revealed something of themselves in talking about their personal research interests, and this may account for the comment of the student who felt closer to his colleagues.

\section{Acknowledgement}

I wish to thank my colleagues who assisted me in teaching this course: Professor David Taylor, Dr. Michael Atkinson, Dr. Francis Creed, Dr. Donald Johnson, Dr Peter Maguire, Dr Frank Margison, Dr Keith Rix and Dr Elemir Szabadi.

\section{REFERENCES}

Crammer, J. (1979) Research in decline. Bulletin, November, pp 174-75.

Creed, F. \& Murray, R. (1981) Teaching of clinical skills. Psychological Medicine (in press)

LEw/s, A. (1961) Psychiatric education and training. Reprinted as Chapter 10 in The State of Psychiatry (1967). Routledge and Kegan Paul.

\section{Children's Legal Centre}

Michael Black, Consultant Psychiatrist in Bedfordshire, writes:

'I learned of the existence of the newly formed Children's Legal Centre while College representative to the International Year of the Child. The idea for the Centre came from a group of lawyers specializing in children's law because it was felt that the expertise of the relatively few lawyers working in this field needed to be made more widely available. The project was sponsored by the UK Association of the International Year of the Child in the hope that the work would continue after the year had ended. This is in fact the case, and fund raising is taking place to enable the Centre to establish itself on a permanent basis. The Centre will provide an advice service covering all matters concerning children and the law, and will also issue publications in order to spread information; hopes to organize courses for various professionals, and generally to increase levels of interest in knowledge of children's law.

The Centre expects to conduct research on specific issues and to provide evidence to parliamentary committees or government departments. It plans to undertake selected test cases in order to clarify the existing law. The Centre will also act as a resort to various groups in order to help them be more effective in their work with children and families. It expects to produce its own register of lawyers who have particular knowledge of children's law.

Some of the issues which may be of relevance to child psychiatrists include the importance of appropriate placement of a child who is in care, the need for such children to have a say in what happens to them, and the position of children in long-stay hospitals or other institutions. The Centre sees a need for child psychiatrists to be willing to act as independent experts with particular reference to care proceedings.'

For those child psychiatrists who are interested further information can be obtained from Naomi Angell or Rachel Hodgkin at: Children's Legal Centre, 2 Malden Road, London, NW5. 